Dept. of Animal Husbandry, Fac. of Vet. Med.,

Sohag University, Sohag, Egypt.

\title{
ASSESSMENT OF FEAR LEVEL IN COMMERCIAL BROILER CHICKEN STRAINS WHEN EXPOSED TO HUMAN CONTACT
}

(With 2 Table and 3 Figures)

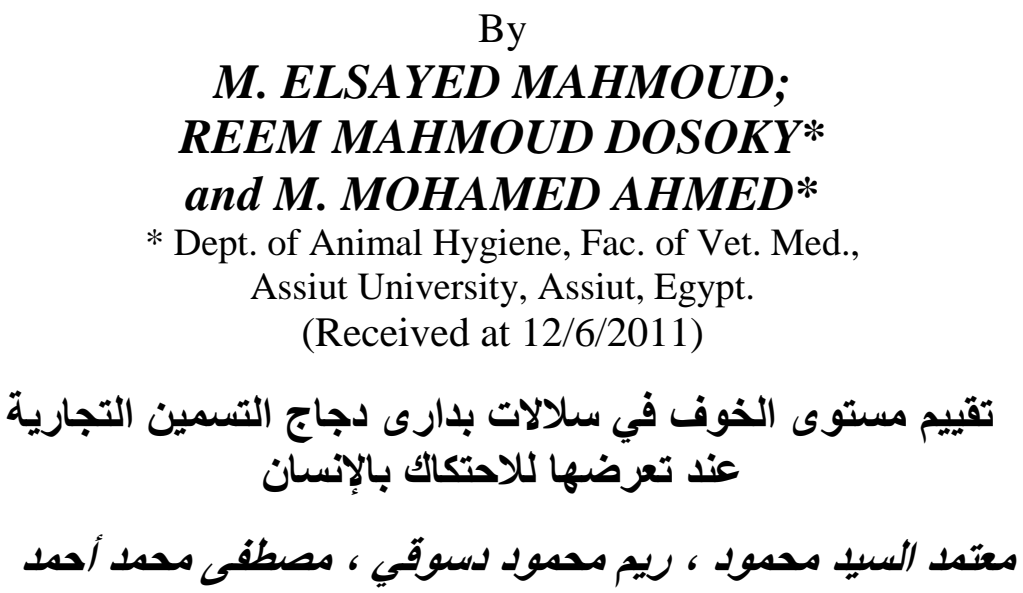

الخلفية البحثية: التعرض للخوف يوثر بالسلب على حالة الإر احة و الكفاءة الإنتاجية في الدجاج

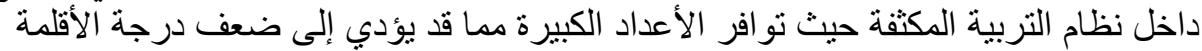

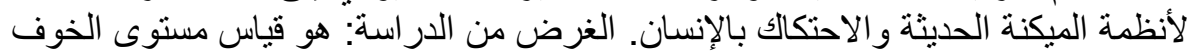

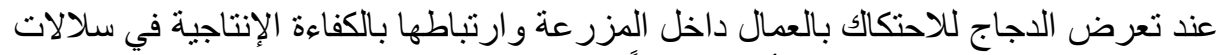

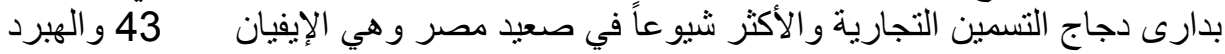

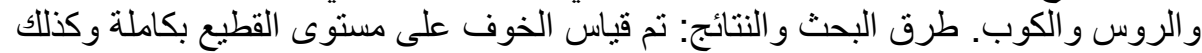

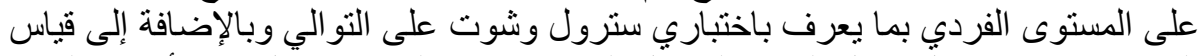

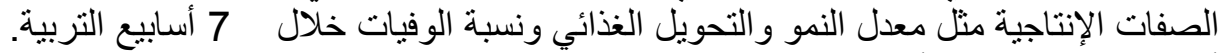

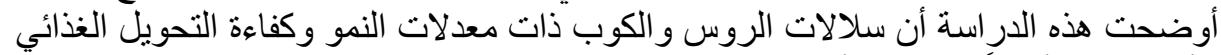

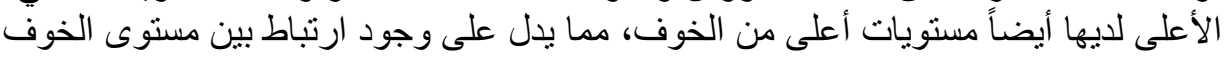

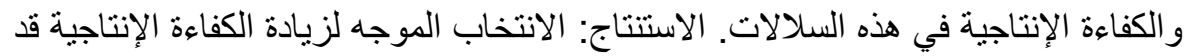

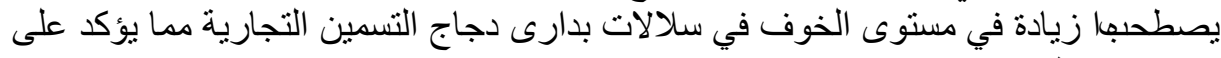
وجود ارتباط إيجابي بينهما.

\section{SUMMARY}

Background: Fear can harm the welfare and productive performance of intensively housed chicks and resulted in lowered fear adaptability to automation and human contact. The purpose: This study was designated 
to measure fear levels to co-workers and its relation to productive performance in the most commonly reared commercial broiler strains (Avian 43, Hubbard, Ross and Cobb) in Upper Egypt when they were kept under intensive rearing conditions. Methods: In this study, measurement of fear levels in broiler strains was investigated according to various test situations. Firstly, using acute fear tests on individual and farm levels to differentiate between strains behaviors, Secondly the productive traits such as growth rate, mortality rate and feed conversion efficiency were measured at farm level during 7 weeks periods. Results: There were significant differences between strains in terms of fear and productive performance $(\mathrm{P}<0.05)$. High fear levels were found to be associated with high productive performance in Ross and Cobb broilers. Conclusion: This study indicated that fearfulness was positively correlated to high productive performance e.g. Body weight gain and feed efficiency. In conclusion, selection towards high productivity could increase fearfulness in Ross and Cobb broilers when compared with Avian 43 and Hubbard.

Key words: Fear tests, performance, Human contact, commercial broiler.

\section{INTRODUCTION}

Fear as an adaptive psycho-physiological response to the perceived danger is considered as an undesirable emotional reaction to the threat of punishment resulting in certain forms of withdrawal behaviors (Jones, 1987 1996). Intense or prolonged fear may have adverse consequences on productivity and welfare of commercial broiler chickens (Duncan, 1990; Hemsworth et al., 1994). There were considerable reports on trials to alter the physiology and behaviors of animals and poultry by regular (a stationary or approaching) human contacts (Hemsworth and Gonyou, 1997; Hemsworth and Barnett, 2000). Researches in poultry farms suggested that reducing the fear level can improve growth rate, feed efficiency and egg production (Jones and Hughes, 1981; Gross and Siegel, 1982; Barnett et al., 1994) and increase resistance to Escherichia coli infection and antibody production (Gross and Siegel, 1982). Broiler strains with high feed conversion efficiency and high meat yield in short periods were termed commercial broilers. In association with these favorable selection responses, the subsequent high mortality rates, strict vaccination programs, drug abuses and greater financial losses continued to increase year after year (Siegel, 1993). 
Since measurement of productive traits under commercial production was impractical and small scale accurate measurement might be away from population values (Dawkins et al., 2004), therefore, selection programs based on simple behavioral tests have already yielded a significant and rapid divergence in underlying fearfulness in chickens and also categorized chicks into high performance and low performance groups when they housed either in small scale groups in a laboratory (Martin et al., 1997) or in large flocks at a commercial farm (Martin et al., 1999). As it is proposed, the approach and avoidance behaviors of animal toward stationary or approaching experimenter provide a useful measure of animal's fear of human (Hemsworth et al., 1994; Cransberg et al., 2000).

In this study individual and field test trials were performed on 4 strains of broiler chicks and its relation to performance under commercial rearing conditions. The present comparative study among most commonly reared commercial broiler strains under field condition was performed to know the best desirable characteristics to enhance further selective breeding.

\section{MATERIALS and METHODS}

1. Subjects and housing: The study was performed in an experimental farm run by Animal and Poultry Production Department, Faculty of Agriculture, Assiut University, Egypt. Each flock composed of 5000 of mixed sex post-hatched broiler chicks. The commercial strains under examination were Avian 43, Hubbard, Cobb and Ross broilers. Each flock stocked in a prefabricated house, equipped with chopped wheat straw bedding, while feed and water were supplied ad libitum. Ambient temperatures were scheduled in a descending gradient $\left(37\right.$ to $\left.24 \mathrm{C}^{\circ}\right)$ and lighting artificially provided by incandescent bulbs (1- $5 \mathrm{watt} / \mathrm{m} 2)$ with (hours; 23.5 L/ 0.5 D) daily light program (Rose, 1997). Vaccinations and medications were scheduled as recommended by manufacturer companies.

\section{Measurement of fear in commercial broiler flocks:}

For assessing the fear in broilers, the birds were subjected experimentally to a fearful situation, observe their behavior and compare such behavior with that appeared under commercial conditions (Duncan, 1981). The first step was performed by using Stroll test and the latter by using modified Plus Maze test or Shute test according to the established 
protocol of Barnett et al. (1994); Cransberg et al. (2000) with slight modifications. Two visits were conducted in each flock. The first visit was at $6^{\text {th }}$ day and the second was at $16^{\text {th }}$ day. These test procedures were repeated three times at the same day (at 7, 15 and 23 o'clock respectively) and average values were calculated (Hemsworth et al., 1994; Cransberg et al., 2000). Birds under investigation did not subject to any negative interactions involving hassling and shouting.

2.1. Stroll test: Stock person approached chicks at both visits and the experimenter followed the stockperson behaved so as not interfere with the husbandry procedure.

2.1.1. Movement phase (Stroll $\mathbf{m}$ ): The experimenter conducted series of 20-steps movement along the length of the farm stopping at approximately one second intervals. At subsequent viewing of the video tape the resultant numbers of birds remaining in the field of view during the movement phase were designated as stroll $\mathrm{m}$.

2.1.2. Stationary phase (Stroll s): After each series of 20 step movements, the experimenter remained stationary for 30 seconds. The mean number of birds remaining in the field of view was designated as Stroll s. The higher scores in Stroll test (Stroll m and Stroll s) the lower was the avoidance behavior or fear level.

2.2. Plus- maze test (Shute test): Forty chicks from the 5000 ones of each strain were randomly captured from locations throughout the farm and weighed to fulfill a search criterion of 20- chicks below (low performance; LP) and 20-chicks above (high performance; HP) 200 grams live body weight. The procedure consisted of placing the tested bird in the most forward position of three areas each measuring $0.4 \times 0.8$ $\mathrm{m}^{2}$ of a table of $0.8 \times 1.8 \mathrm{~m}^{2}$ surface area and $0.7 \mathrm{~m}$ height. After 5 seconds, the experimenter slowly approached the birds at $2.8 \mathrm{~m}$ from the table with hands at his sides and he stopped for 5 seconds at $1.6 \mathrm{~m}, 0.8 \mathrm{~m}$ and $0.0 \mathrm{~m}$ from the table respectively. At each 0.8 increments the bird's position designated as Tofs in directions; forward (0) side (1) and rear (2). The bird's orientation designated as Tafs in directions; forward (0), side (1) and rear (2) of each bird were recorded. The higher the scores in Shute test the greater was the avoidance behavior or fear level.

\section{Measurement of productive traits:}

Forty chicks from 5000 ones were captured at random from the previously mentioned four strains for measurement of productive traits and returned again to the main flock after measurement. Besides, daily number of birds found dead, mortality per week, weighing at arrival and 
on weekly basis up to seven weeks and feed consumption were measured. Body weight gain and feed efficiency ( $\mathrm{kg}$ of feed required for each $\mathrm{kg}$ gain in body weight) were also calculated.

\section{Statistical analysis:}

All statistical analysis of data was performed using SPSS (2007) Software. All values were presented as means \pm standard error (SEM). Descriptive statistics of age groups in 4 broiler strains were analyzed by one way analysis of variance (ANOVA) for Stroll and Shute test. Twoways ANOVA were used for analyzing quantitative traits (4 strains X 7 ages). Tukey's HSD was used for multiple comparisons among mean values in different broiler strains.

\section{RESULTS}

\section{Measurement of fear in commercial broiler flocks:}

The number of birds remaining in the field of view during the movement of experimenter (Stroll $\mathrm{m}$ ) and the number of birds approaching or remaining near stationary experimenter in the approaching human test (Stroll s) were significantly $(P<0.05)$ higher in Ross and Cobb strains when compared with Avian 43 and Hubbard strains. In stroll test, it was observed that the high number of birds remaining near the approaching human in Ross broilers was associated with a low number of birds withdrawing or orienting away from approaching experimenter in the Shute test. Also high fear levels were associated with high feed conversion efficiency and mortality percent (Table 2).

Table 1: Fear level in commercial broiler flocks.

\begin{tabular}{|c|c|c|c|c|c|c|}
\hline \multicolumn{2}{|c|}{} & Avian 43 & Hubbard & Ross & Cobb \\
\hline \multirow{2}{*}{$\begin{array}{c}\text { Farm Test } \\
\text { Stroll })\end{array}$} & Item & $37.05 \pm 3.1^{\mathrm{a}}$ & $36.65 \pm 3.4^{\mathrm{a}}$ & $26.1 \pm 2.65$ & $29.35 \pm 2.15$ \\
\cline { 2 - 7 } & Stroll s & $35.1 \pm 3.1^{\mathrm{a}}$ & $34.65 \pm 2.9^{\mathrm{a}}$ & $24 \pm 2.1$ & $27.35 \pm 1.8$ \\
\hline \multirow{2}{*}{$\begin{array}{c}\text { Individual } \\
\text { Test } \\
\begin{array}{c}\text { (Shute test) } \\
$\cline { 2 - 7 }\end{array}\end{array}} & HP & Tofs & $31 \pm 1.1$ & $37 \pm 1.5^{\mathrm{a}}$ & $44 \pm 2.5^{\mathrm{b}}$ & $42 \pm 2.1^{\mathrm{b}}$ \\
\cline { 2 - 7 } & LP & Tofs & $32 \pm 4.3^{\mathrm{ab}}$ & $24 \pm 3.4$ & $21 \pm 3.3$ & $27 \pm 4.0^{\mathrm{b}}$ \\
\cline { 2 - 7 } & Tafs & $10 \pm 2.3$ & $8 \pm 2.0$ & $16 \pm 2.1^{\mathrm{a}}$ & $15 \pm 1.8^{\mathrm{a}}$ \\
\hline
\end{tabular}


One-way ANOVA revealed a significant effect of strain differences. Post hoc Tukey's HSD tests indicated significant differences between Ross and Cobb when compared with Hubbard and Avian 43. Strolls, Strollm, Orientation and position scores and the mean values of Tofs and Tafs score (Shute test) in four broiler strains are shown. Data are presented as means and standard error bars (SEM.) and values with different letter superscripts means significantly different $(P<0.05)$.

2. Measurement of productive traits in commercial broiler flocks:

\subsection{Body weight gain:}

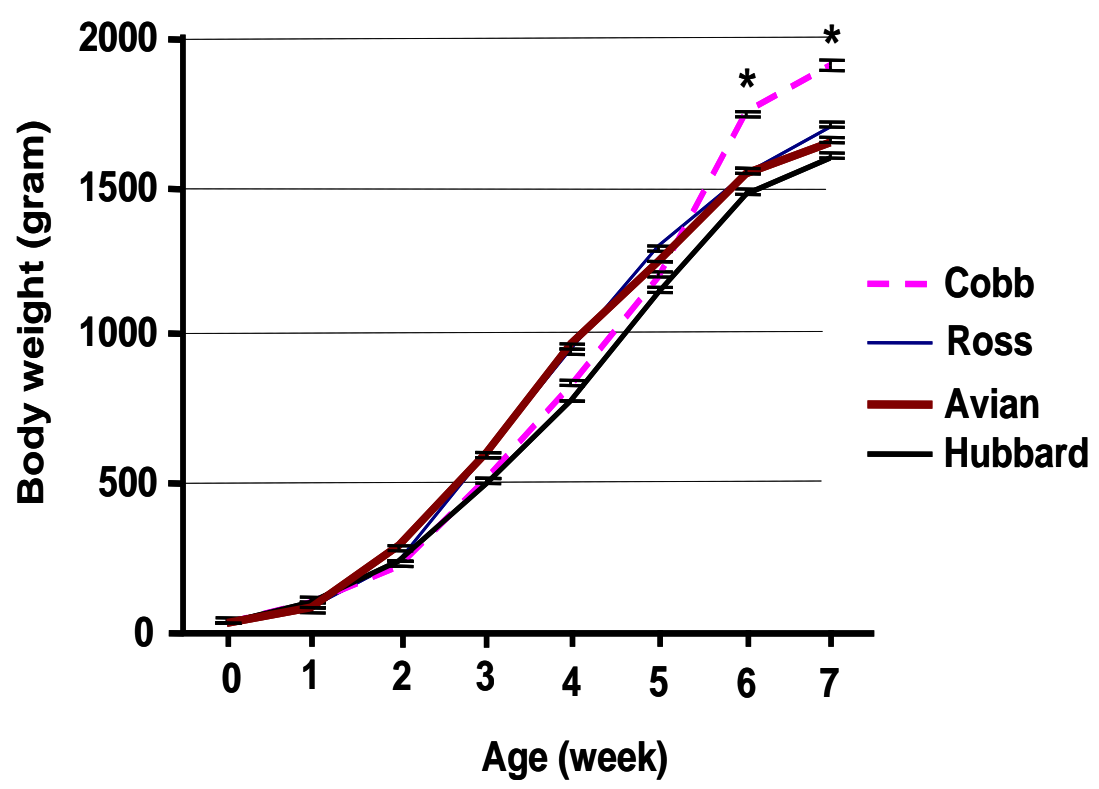

Fig. 1: Growth curves during 7 weeks period in four broiler strains. Body weights in grams during 7 weeks period were calculated. Values with asterisks mean significant $(\mathrm{P}<0.05)$ differences in Tukey's HSD tests.

Considering body weight during 7 weeks rearing, Cobb broilers had greater body weight than other strains on $6^{\text {th }}$ and $7^{\text {th }}$ weeks $(\mathrm{P}<0.05)$ (Fig.1)

\subsection{Feed conversion efficiency}




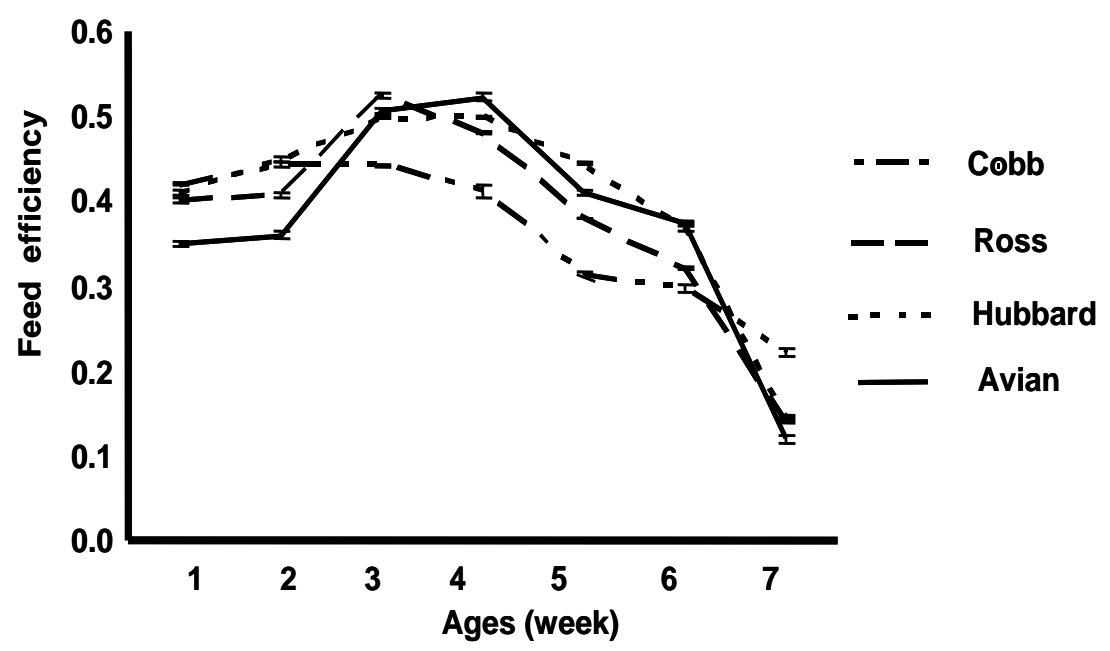

Fig. 2: Time course of feed efficiency during 7 weeks period in four broiler strains. Feed conversion efficiency was calculated weekly based on body weight gain and feed consumption in grams. Two ways ANOVA indicated no age and strain effect on feed efficiency.

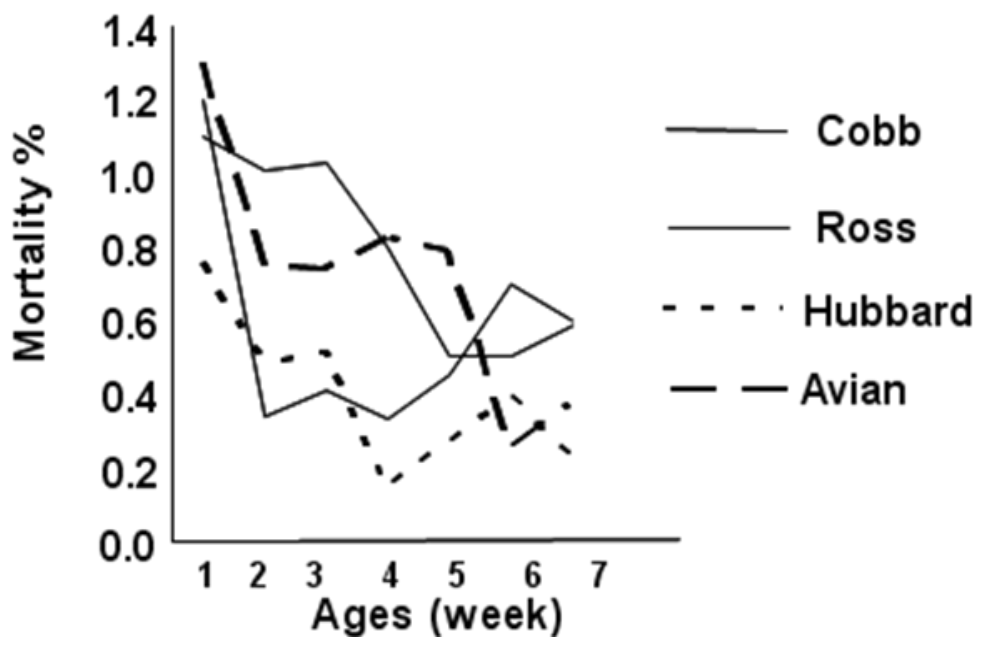

Fig. 3: Time course of mortality percentages (\%) during 7 weeks period in four broiler strains. Numbers of birds dead were calculated as a percent of total number on weekly basis. Tukey's HSD test indicated that Hubbard and Ross had higher mortality percentages during $2^{\text {nd }}, 3^{\text {rd }}$ and $4^{\text {th }}$ weeks than other strains. 
It was noticed that Ross and Cobb broilers had higher weight gain, feed conversion efficiency but also high mortality percentages.

Table 2: Summarizes the performance and mortality data. Significant treatment differences were noted for body weight gain on day 49th. Cobb broilers had greater body weight gain than other strains. Cobb and Ross had higher feed conversion efficiency than other strains.

\begin{tabular}{|c|c|c|c|c|}
\hline Strain & Avian 43 & Hubbard & Ross & Cobb \\
\hline $\begin{array}{c}\text { Body Gain } \\
\text { (gram/bird/day) }\end{array}$ & $33.67 \pm 0.65$ & $33.67 \pm 0.72$ & $34.69 \pm 0.89$ & $39.19 \pm 0.94^{\mathrm{a}}$ \\
\hline Feed Efficiency & $0.37 \pm 0.004$ & $0.36 \pm 0.003$ & $0.40 \pm 0.002^{\mathrm{a}}$ & $0.43 \pm 0.002^{\mathrm{a}}$ \\
\hline Total Mortality (\%) & $5.03^{\mathrm{a}}$ & 2.67 & $4.03^{\mathrm{b}}$ & $5.20^{\mathrm{a}}$ \\
\hline
\end{tabular}

\section{DISCUSSION}

The results of behavioral tests suggested that the withdrawal response of chicks to an experimenter in standard test may be a useful behavioral measure of the bird fear to human. First, Ross and Cobb broilers displayed greater withdrawal response to humans than Avian and Hubbard, while Avian 43 and Hubbard broilers showed the lower withdrawal as indicated by orientation values (Table 1). It is reported that Stroll test is more feasible and practical in commercial flocks than regular handling of every bird as in Shute test (Zulkifili et al., 2002).

The whole performance values found in this study (Fig. 1, $2 \& 3$ and Table 2) were within the range reported about broilers (Zubair and Leeson, 1996; Mignon et al., 1999). Who they measured body weight gain feed conversion and mortality rate in Ross broilers as following: 28.1 grams/ bird/day, 0.69 and $12.5 \%$ respectively. While in Hubbard broilers the results were: $29.5 \mathrm{grams} / \mathrm{bird} /$ day and $0.77,2.08 \%$ with respect to body weight gain, feed conversion and mortality rate respectively.

Data published by Jones and Hughes, 1981; Gross and Siegel (1982); Barnett et al. (1994) was consistent with the bad effect of fearfulness on growth performance of chicken. In the context of poultry 
production these findings provide a tool to exclude the strains of broilers which exhibits inability to cope with environmental stressors. Low adaptability to fear is reflected by direct impact on most managemental procedures such as birds capture and translocation of chicks from brooding cages to growing pens and exposure to human. Therefore it is possible to accept the higher mortality percentages $(\%)$ in $2^{\text {nd }}, 3^{\text {rd }}$, and $4^{\text {th }}$ weeks of age in Ross and Cobb broilers (Fig.3).

The findings of the present study demonstrated a strong relationship between fear and productivity within different broiler strains. The obtained results were generally in agreement with (Jones, 1996; Hemsworth and Barnett, 2000) who stated that there was a positive correlation between fearfulness and productivity in poultry. The mechanism responsible for the association between productivity and fearfulness is still unclear. However, in the view of similarities in experience of stockmen, environmental and nutritional factors among stains, variations in the genetic background are likely to be highly influential. Therefore, results reported herein, strengthen the notion that fear could be used as a marker to differentiate between higher and lower production strains (Martin et al., 1997 and 1999).

In conclusion: The behavioral measures in the present study provided further evidence that fearfulness is directly related to performance in chicken and the behavioral tests fulfill a useful selection criterion for future selection programs against undesirable characteristics.

\section{REFERENCES}

Barnett, J.; Hemsworth, P.; Hennessy, D. and McCollum, T. (1994): The effects of modifying the amount of human contact on behavioral, physiological and productive responses of laying hens. Appl Anim Behav Sci. 41: 87-100.

Cransberg, P.H.; Hemsworth, P.H. and Coleman, G.J. (2000): Human factors affecting the behavior and productivity of commercial broiler chickens. Br. poult.Sci. 41 (3): 272-279.

Dawkins, M.S.; Donelly, C.A. and Jones, T.A. (2004): Chicken welfare is more influenced by housing conditions than by stocking density. Nature. 22: 427(6927): 342-344.

Duncan, I.J.H. (1981): Animal rights-Animal welfare: Scientist's assessment. Poul. Sci. 60: 484-499. 
Duncan, I.J.D. (1990): Reactions of poultry to human beings. In: R.Zayan and R. Danzer (Editors), Social stress in domestic animals Kluwer Academic, Dortdrecht, pp.121-131.

Gross, W.B. and Siegel, P.B. (1982): Socialization as a factor in resistance to infection, feed efficiency and response to antigen in chickens. Am. J. Vet. Res. 43: 2010-2021.

Hemsworth, P.H. and Barnett, J.L. (2000): Human and animal interaction and animal stress In: Moberg, G.P, Mench, J.A (Eds), The biology of animal Stress. Basic principles and implications for animal Welfare.CAB International, Wallingfort, pp. 205-217. Implications and imperatives. World's poult. Sci. Journal. Vol. 52: 131-174.

Hemsworth, P.H. and Gonyou, H.W. (1997): Human contact In. Appleby, M.C.; Hghes, B.O. and Elson, H.A. (Eds): Poultry production systems. Behavior, Management and Welfare. C.A.B. International.pp.40-81.

Hemsworth, P.; Coleman, G.J.; Barnett, J.L. and Jones, R.B. (1994): Behavioral responses to human and the productivity of commercial broiler chickens. Appl. Anim Behav. Sci. 41: 101-114.

Jones, R.B. (1996): Fear and adaptability in poultry: insights, implications and imperatives. World's Poult. Sci. J. 52: 131-174.

Jones, R.B. (1987): The assessment of fear in domestic fowl. In: R. Zayan and I.J.H Duncan (Editors) Cognitive aspects of social behavior I- in the domestic fowl. Elsevier, Amsterdam, pp. 40-81.

Jones, R.B. and Hughes, B.O. (1981): The effect of regular handling on growth in male and female chicks of broiler and layer strains $\mathrm{Br}$. Poult. Sci., 22: 461-465.

Martin, R.H.; Arce, A. and Martijina, I.D. (1997): T-maze performance and body weight relationship in broiler chicks. Appl. Anim. Behav. Sci. 54: 197-205.

Martin, R.H.; Jones, R.B.; Carcia, D.A. and Arce, A. (1999): Early Tmaze behavior and subsequent growth in commercial broilerflocks. Br. Poult. Sci. 40: 434-438.

Mignon, S.; Beaumont, C; LeBeihan-Duval, E.; Poivey, J.; De Rochambeau, H. and Ricard, F. (1999): Genetic parameters of growth curve parameters in male and female chickens. Br. Poult. Sci. 40: 44-51. 
Rose, S.P. (1997): Principles of poultry science. Chapter g: PP. 117-128. C.A.B. International Wallingford. Oxon. U.K.

Siegel, P.B. (1993): Behavior-Genetic Analyses and poultry Husbandry. Poultry Science 72: 1-6.

SPSS (2007): Statistical Package for Social Science, version 16 (2007) for Window.

Zubair, A. and Leeson, S. (1996): Compensatory growth in the broiler chicken: a review. World's poultry Science Association. 52: 189-201.

Zulkifili, I.; Gilbert, J.; Liew, P.K. and Ginsos, J. (2002): The effect of regular visual contact withhuman bing on fear, stress, antibody and growth responses in broiler chickens. Appl. Anim. Behav. Sci. 79: 103-112. 